\title{
Screening for malignant melanoma-a critical assessment in historical perspective
}

\author{
Wolfgang Weyers ${ }^{1}$
}

1 Center for Dermatopathology, Freiburg, Germany

Key words: melanoma, screening, overdiagnosis

Citation: Weyers W. Screening for malignant melanoma-a critical assessment in historical perspective. Dermatol Pract Concept. 2018;8(2):89-103. DOI: https://doi.org/10.5826/dpc.0802a06

Received: November 6, 2017; Accepted: December 19, 2017; Published: April 30, 2018

Copyright: $\odot 2018$ Weyers. This is an open-access article distributed under the terms of the Creative Commons Attribution License, which permits unrestricted use, distribution, and reproduction in any medium, provided the original author and source are credited.

Funding: None.

Competing interests: The authors have no conflicts of interest to disclose.

All authors have contributed significantly to this publication.

Corresponding author: Wolfgang Weyers, MD, Center for Dermatopathology, Engelbergerstr. 19, 79106 Freiburg, Germany. Tel. 01149761-31696; Fax. 01149-761-39772. Email: ww@zdpf.de

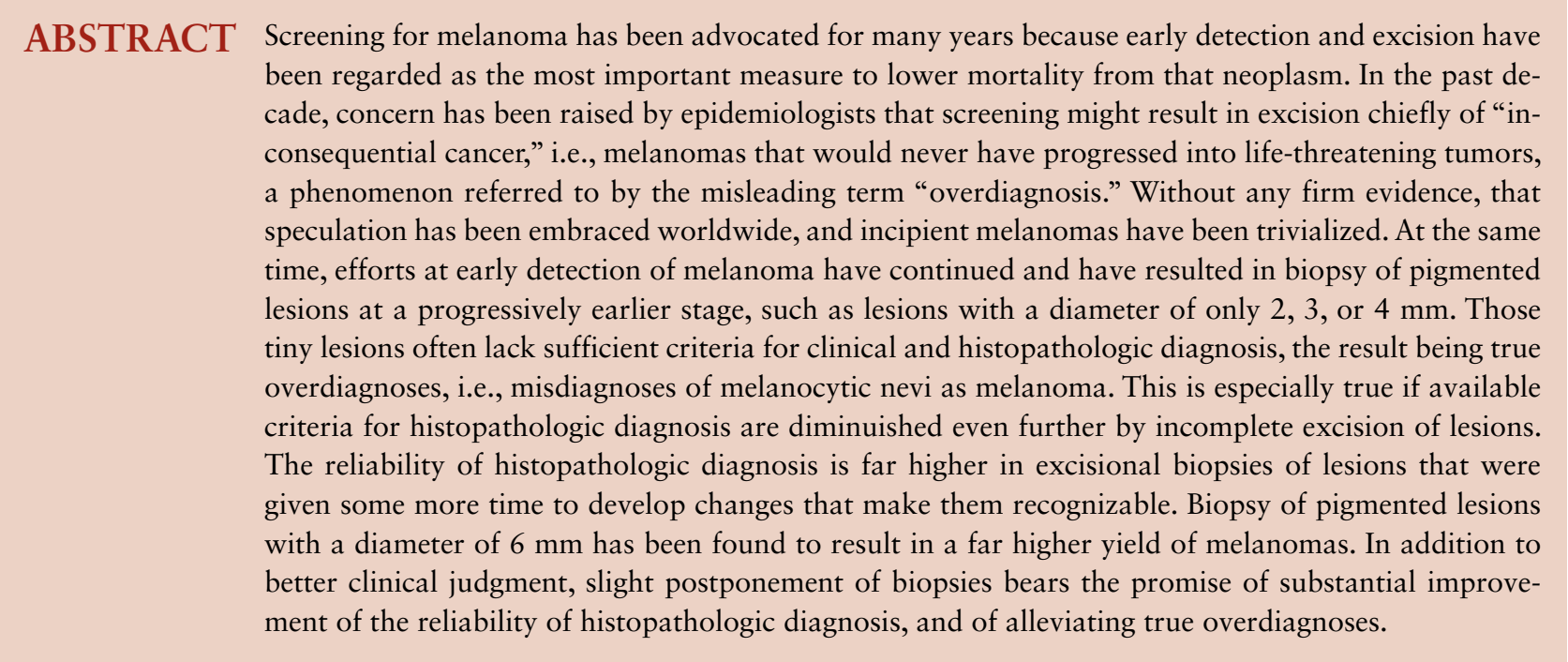

\section{Noli Me Tangere}

Noli me tangere, do not touch me, is a phrase from the Bible. In the Latin translation of the Gospel according to John, Jesus spoke those words to Mary Magdalene after his resurrection to prevent her from touching him. Over the centuries, that phrase was transferred from the Biblical tale to other spheres, such as sensitive issues that were dangerous to tackle, as in the novel Noli Me Tángere by José Rizal, one of the national heroes of the Philippines. The novel portrayed corruption and abuse by the Spanish colonial government and the Catholic Church, and Rizal was executed a few years after its publication for the crime of rebellion. In medicine, noli me tangere warned of touching malignant neoplasms, especially malignant melanoma for which noli me tangere became a synonym. In the 
late 19th century, any active treatment of melanoma was discouraged. For example, Moriz Kaposi cautioned that, "according to experience, extirpation even of the very first nodules cannot arrest further progress. Hence, the procedure is carried out only rarely, and the very first symptom of pigmented cancer is regarded as an ominous sign of a rapidly deleterious course" [1]. In 1933, Guido Miescher noted that surgical treatment for melanomas was "more and more abandoned at least for primary tumors because the danger of acute dissemination is doubtlessly high, and cases with acute aggravation following surgical procedures have been observed repeatedly" [2]. As late as in the 1960s, those fears had not been overcome. As stated in Gottron's handbook of dermatalogy and venerology, "until recently, management followed the principle of 'noli me tangere' that regarded any therapeutic procedure as malpractice. Today, treatment has entered an active stage but an agreed-upon therapeutic approach has not emerged" [3].

\section{Establishment of Clinical and Histopathologic Criteria for Recognition of Incipient Melanoma}

The last decades of the 20th century witnessed a radical paradigm shift. Therapeutic restraints were replaced by the conviction that melanomas must be detected and exstirpated as early as possible, not as an exophytic nodule but as a tiny papule, not as a papule but as a macule. For decades, the macular stage of melanoma had been misinterpreted as a benign nevus that, according to accepted wisdom, underwent "malignant transformation" when a nodule of melanoma developed on it. For example, in 1953, Allen and Spitz described typical histopathologic signs of melanoma in situ, including: “(1) the general features of nuclear anaplasia such as hyperchromatism, increase in nuclear and nucleolar size, irregular nuclear vacuolization, and mitotic figures; (2) subepithelial inflammatory reaction consisting prepoderantly of lymphocytes; and (3) cytoplasmic vacuolization and fine melanin pigmentation reaching to the uppermost layers, that is, to the stratum granulosum and stratum corneum." They concluded, nonetheless, that "the decision as to whether or not a given lesion is to be diagnosed an active junctional nevus or a melanocarcinoma must ... depend on this single fact: THE PRESENCE OR ABSENCE OF DERMAL INVASION” [4].

It took many years to realize that the vast majority of melanomas start in the anatomic structure that harbors melanocytes physiologically, namely, the epidermis, and that they can be recognized there. In a histopathologic study of melanoma in 1958, Lane et al described melanoma in situ under the name "purely junctional malignant melanoma."
[5] Four years later, Lund and Kraus alluded to nests at the dermo-epidermal junction of melanoma that were "often large, confluent, horizontally extended, and loosely cellular" [6]. In 1976, Price, Rywlin and Ackerman advanced criteria for histopathologic diagnosis of melanoma "on the basis of proven metastases." Most of those criteria pertained to changes in the epidermis, such as "poor circumscription of the intraepidermal melanocytic component of the lesion with lateral extension of individual melanocytes" and "marked variation in shape and size of the melanocytic nests" [7]. In subsequent publications by Ackerman, additional criteria were established, e.g., asymmetry and extension of melanocytes deep down adnexal epithelia [8].

Those criteria not only enabled melanoma to be diagnosed at an early stage but also resulted in marked improvement of clinico-pathologic correlation. In 1952, Martin Swerdlow of Chicago deplored the "recurring discrepancy between the clinical and pathologic diagnosis of nevus or pigmented mole." Of 57 lesions diagnosed clinically as melanoma, only 16 (28\%) were said to be melanomas histopathologically, and of 27 melanomas diagnosed histopathologically, only $59 \%$ had been diagnosed clinically as melanoma [9]. Because of new criteria for histopathologic diagnosis established in subsequent decades, the correct clinical diagnosis was confirmed far more often histopathologically, and the more dependable histopathologic diagnoses drew the attention of clinicians to clinical aspects of melanoma that had been neglected previously. In 1985, Friedman, Rigel, and Kopf advanced the "ABCD" rule for "early detection of malignant melanoma”: A for "Asymmetry," B for "Border irregularity," C for "Color Variegation," and D for "Diameter generally greater than $6 \mathrm{~mm}$ " [10].

Those criteria were not very specific because they were also fulfilled, in moderate degree, by many melanocytic nevi. Their sensitivity, however, was higher because most melanomas display irregularities in their general architecture, outline, and coloration, once having reached a diameter of $6 \mathrm{~mm}$. More importantly, melanomas at that stage are nearly always thin and often still confined to the epithelium so that a simple excision results in permanent cure. The early detectability and treatability of melanoma prompted Ackerman to demand in 1985 that "no one should die of malignant melanoma" [11].

\section{Introduction of Screening for Melanoma}

Because of direct visibility and detectability at an early stage and usually slow growth, melanoma came to be viewed as a "model for cancer education and prevention" and an "ideal screening tumor" $[12,13]$. Criteria for diseases qualify- 
ing for screening procedures had been formulated by Wilson and Jungner in a "public health paper" of the World Health Organization in 1968, namely: “(1) The condition sought should be an important health problem. (2) There should be an accepted treatment for patients with recognized disease. (3) Facilities for diagnosis and treatment should be available. (4) There should be a recognizable latent or early symptomatic stage. (5) There should be a suitable test or examination. (6) The test should be acceptable to the population. (7) The natural history of the condition, including development from latent to declared disease, should be adequately understood. (8) There should be an agreed policy on whom to treat as patients. (9) The cost of case-finding (including diagnosis and treatment of patients diagnosed) should be economically balanced in relation to possible expenditure on medical care as a whole. (10) Case-finding should be a continuing process and not a 'once and for all' project" [14]. Those criteria were subsequently supplemented and specified: the disease must have serious consequences and a high prevalence in order to justify screening efforts, and it must progress slowly and not be immediately life threatening $[15,16]$. All those conditions are fulfilled by melanoma.

By that time, the first campaigns for prevention and early detection of melanoma were already under way. In 1963, Neville Davis of Princess Alexandra Hospital in Brisbane started the "Queensland Melanoma Project," a clinical and histopathologic study with long-term follow-up of patients and an associated public campaign for melanoma prevention [17]. Because of the high prevalence of skin cancer among the fair-skinned population exposed to a tropical climate, Australia pioneered efforts at skin cancer prevention. In 1981, the Cancer Council of Victoria started the "SLIP! SLOP! SLAP!" campaign ("Slip on a shirt! Slop on a sunscreen! Slap on a hat!”) that aimed at primary prevention, i.e., prevention of the development of skin cancer, but also included efforts at secondary prevention, i.e., early detection and treatment. Several other campaigns followed $[18,19]$. After a continuous rise in the incidence of age-specific melanoma for many decades, together, these campaigns likely were responsible for a decrease in the age-specific melanoma incidence in Australia, the first country worldwide to note a decrease. However, those effects are still shrouded by an absolute increase in the number of detected melanomas due to demographic aging [20] (Figure 1).

The Australian model was copied in the southern United States, where Jack Redman of Albuquerque in 1977 started the New Mexico Melanoma Project [21]. As in Australia, the population was informed through leaflets and TV spots about the risks associated with UV exposure and the identifying features of melanoma. Cartoon characters like "Sid Seagull" in Australia and a mole in New Mexico (reflecting the synonymous use of the word for pigmented lesions) targeted especially children and youth (Figures 2, 3). In 1979, the Skin Cancer Foundation was founded in New York City and it released a series of publications that alerted physicians and the laity to the danger of excessive exposure to ultraviolet light as the most important influenceable risk factor for melanoma and to criteria for early recognition of melanoma in a booklet titled, The Many Faces of Malignant Melanoma and a leaflet about the "ABCDs of Moles \& Melanomas" (Figure 4).

The rising incidence of melanoma also led to efforts at prevention and early detection in other countries with a predominantly fair-skinned population. For example, in 1982, a skin cancer comic book distributed in Hawaii resulted in a more reserved attitude toward sun exposure [22]. Similar effects were seen in Sweden and England following educational campaigns

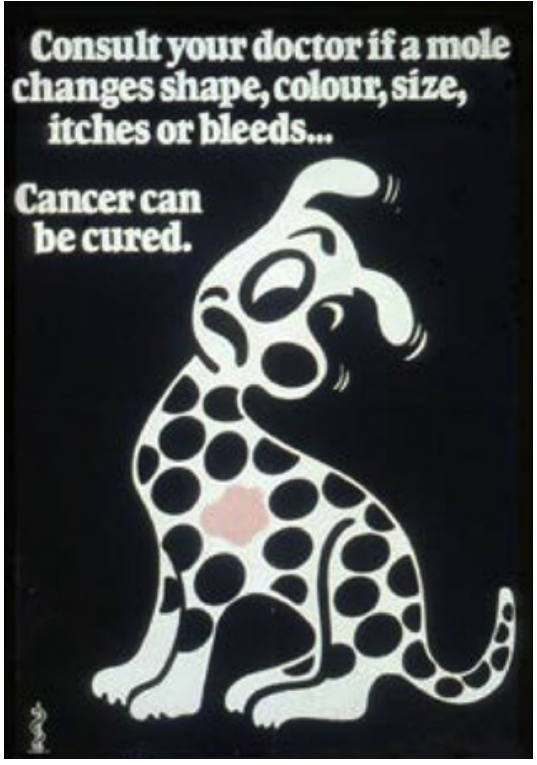

Figure 1. Poster of the Sydney Melanoma Unit in the 1990s.

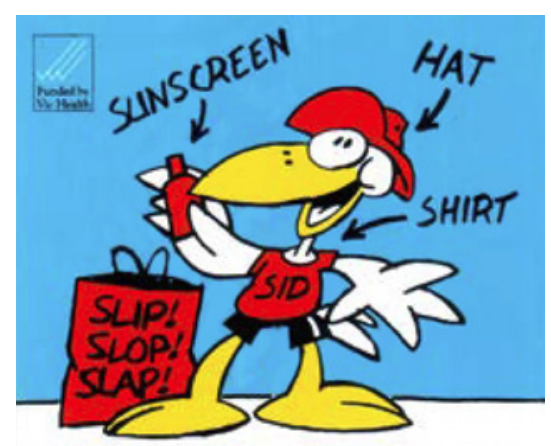

Be SunSmart like Sid Seagull

† Anti-Cancer Council of Yistoria

Figure 2. "Sid Seagull" as a teacher of cautious sun exposure in the Australian "SunSmart" campaign.

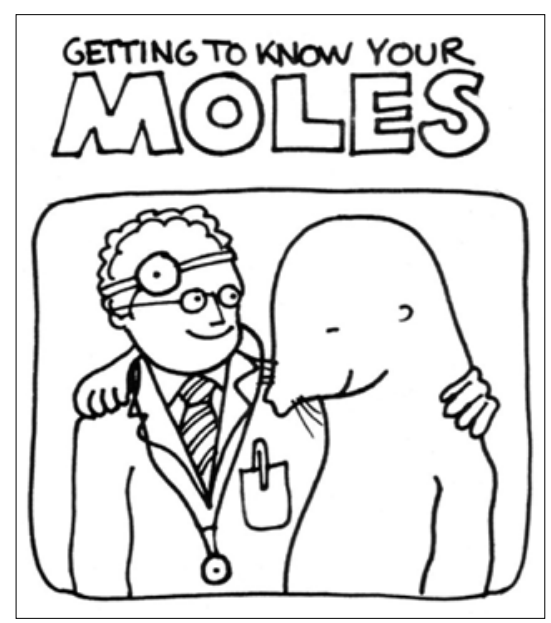

Figure 3. "Getting to know your moles". First American publication for melanoma education by the New Mexico Melanoma Project in the late 1970s. 
[23, 24]. In Germany, the Giessen Melanoma Group started an educational campaign in 1980 , referring to melanoma as "black cancer" and "a wolf in sheep's clothing” [25] (Figure $5)$. Those activities were pursued at a national level by the Commission for Early Detection and Prevention of Skin Cancer that was founded in 1987 [26]. In addition to educational efforts in numerous brochures and leaflets, the commission inaugurated a oneyear pilot study of population-based skin cancer screening in the state of Schleswig-Holstein that began in 2003 aimed at "preponing the point of diagnosis as far as possible... through population-based, area-wide skin cancer screening, in order to reduce morbidity and mortality and costs in the health care system" [27]. Eventually, 19\% of the population made use of the offer of free screening examinations, leading to a rise in the incidence of melanoma of about one third and to a significant reduction in mortality after five years. The results of that study contributed to the decision to implement populationbased skin cancer screening in Germany. Since mid-2008, free skin cancer screening is offered to all adults over 34 years of age every two years under the scope of public health insurances [28].

Most studies about melanoma screening failed to detect a positive effect on mortality, and in Germany, the positive trend could not be substantiated in follow-up studies [29]. However, mortality remained at least relatively stable despite a marked increase in the incidence of melanoma. The latter was attributed to factors such as greater sun exposure during recreational activities, use of solariums, travel to tropical countries, and depletion of the ozone layer of the stratosphere [28,30,31]. In the United States, an increase in the incidence of melanoma between 1975 and 2010 of almost $200 \%$ contrasted with an increase of only $32 \%$ in mortality [32]. That discrepancy was perceived as a success of cancer screening

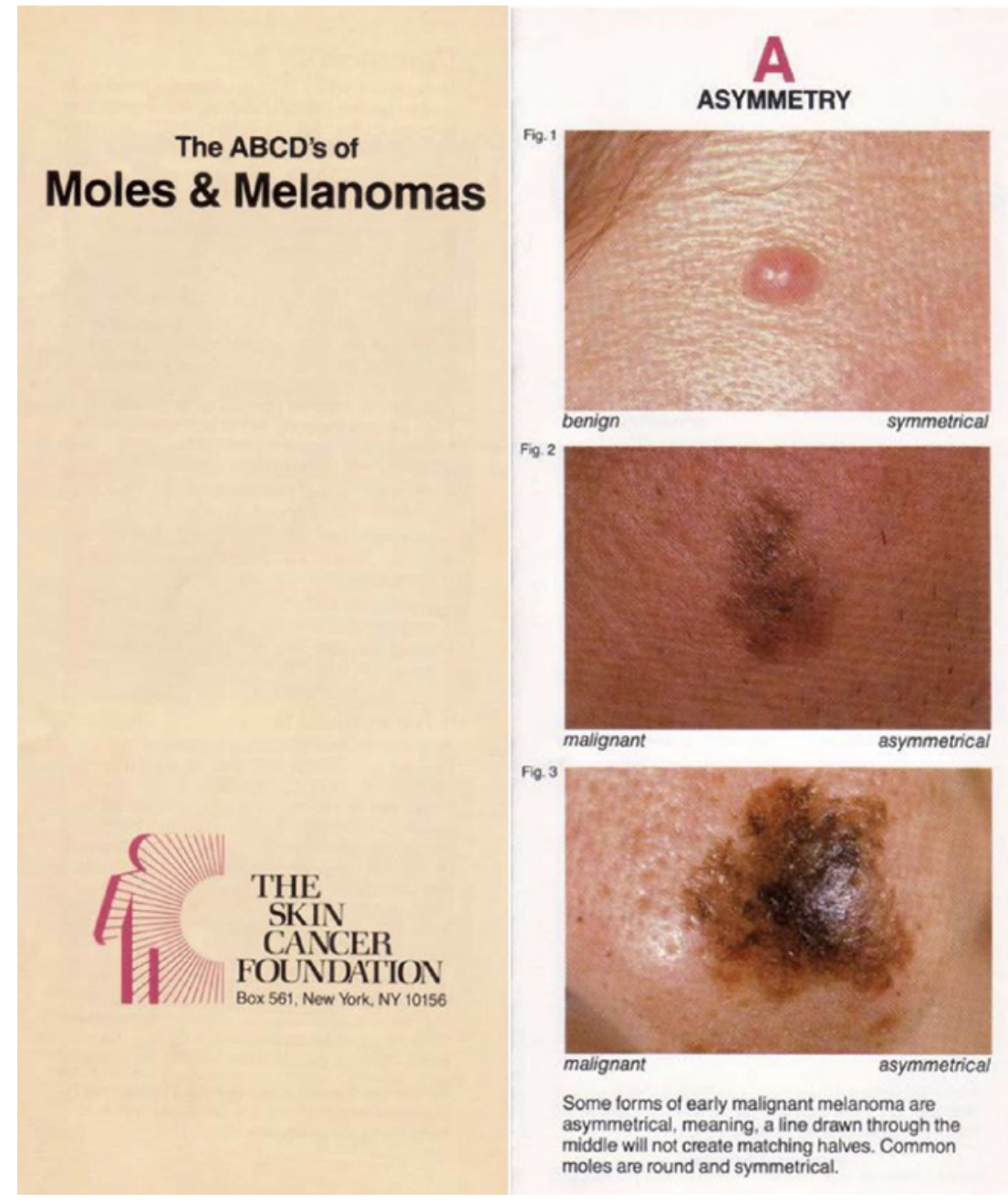

Figure 4. "The ABCDs of Moles \& Melanomas". Leaflet of the American Skin Cancer Foundation in 1985.

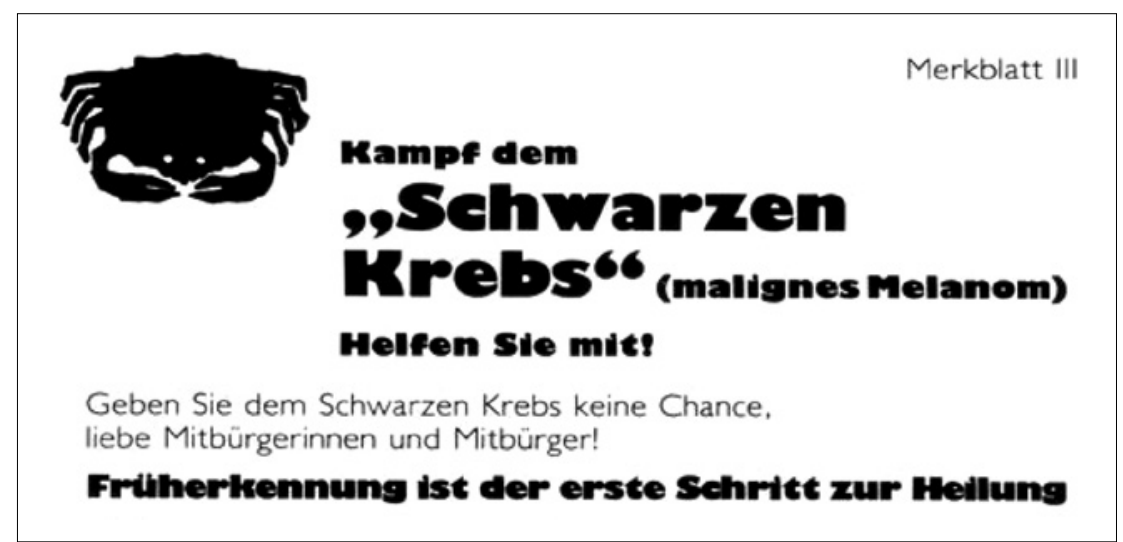

Figure 5. "Fight Against Black Cancer". Leaflet of the Giessen Melanoma Group in the mid 1980s.

[33]. When patients with early-stage melanomas came to consultation hours following the first German melanoma campaign in Giessen in the early 1980s, they were said to "probably owe their life to the campaign" [25], and this was probably true for some of them. The conclusion seemed obvious: if one succeeded at detecting an even higher percentage of melanoma at an early stage, this would eventually lead to a decrease in mortality. 


\section{Improvement of Methods for Early Clinical Recognition of Melanoma}

Those considerations led to enhanced efforts at early detection of melanoma. The latter included not only educational campaigns and screening examinations but also improvement of clinical diagnosis. Clinical examination of the skin by a trained physician fulfilled the screening requirement of "a suitable test or examination ... acceptable to the population" [14], but sensitivity and specificity were limited; most studies revealed a sensitivity of about $80 \%$ and a specificity of about $70 \%$ [34-36]. The ABCD criteria were criticized because many nevi and seborrheic keratoses fulfilled them, and they did not encompass the early stage of nodular melanomas [37]. For the latter, change of a pigmented lesion was the most important identifying feature. This led to supplementation of the ABCD rule by another letter, namely, "E" for "enlargement," "elevation," or "evolving." The latter term came to be preferred because it included any type of change [38]. In order to detect changes of moles in patients with myriad pigmented lesions, total body photography was introduced in 1988, rendering possible a comparison with the previous state at each new consultation [39].

In addition to the $\mathrm{ABCDE}$ rule, other formulas were advanced for clinical detection of melanomas, such as the "three Cs" ("color, contour, change") or the "Glasgow 7-point checklist" of 1990 that included, as major criteria, change in size, change in shape, and change in color, along with four minor criteria, namely, diameter $\geq 7 \mathrm{~mm}$, inflammation, crusting or bleeding, and sensory change [40]. Because of its more complex nature, the "7-point checklist" did not become as popular and widely used as the ABCDE rule [41]. A criterion not pertaining to the individual lesion is the "ugly duckling sign." First described in 1998, the sign implies that a pigmented lesion differing from all other lesions of a given patient is likely to be a melanoma [42]. The importance of that "intrapatient comparative analysis" has been substantiated by several studies [43].

In addition to refinement of criteria for clinical diagnosis of melanoma, several technical advances enhanced precision of diagnosis. Most important was the introduction of the dermatoscope that enabled the surface of lesions to be studied in ten-fold magnification and with reduced scatter of light (application of fluid enables immediate contact of the lens to the skin surface). Hence, anatomic structures could be assessed down to the papillary dermis, and the distribution of pigment and vessels could be assessed far better than by the naked eye. Among the criteria established for dermatoscopy were assessment of different dermatoscopic patterns in "pattern analysis" [44]; the "ABCD rule of dermatoscopy" that assessed asymmetry, borders, coloration, and "different structural components" according to a point rational scheme
[45]; the "Menzies method" that considered symmetry and monochromacity to be exclusion criteria for melanoma [46]; a "7-point checklist" with three major and four minor criteria [47]; a simplified "3-point checklist" [48]; and the $\mathrm{CASH}$ algorithm that emphasized the importance of "color, architecture, symmetry, and homogeneity" for the assessment of melanocytic neoplasms [49]. Moreover, dermatoscopy enabled assessment of the development of lesions by following their natural course-far more precise a technique than conventional clinical examination or anamnestic data [50]. Irrespective of the recognition scheme, dermatoscopy has the potential of enhancing the sensitivity and specificity of clinical diagnosis of melanoma substantially. However, it requires some experience, and without it, it may lead to undesired results [51].

In order to overcome subjectivity and lack of experience in the assessment of dermatoscopic images, computer-based evaluation programs have been developed. Computers with deep convolutional neural networks trained by thousands of images and corresponding diagnoses have been found to reach a performance that matches the level of experienced dermatologists [52,53]. Such programs may assist especially in the laborious evaluation of images obtained by total body photography in patients with myriad pigmented lesions [54]. Additional techniques employed to enhance precision in clinical diagnosis include confocal laser microscopy that enables high resolution imaging of the epidermis and upper dermis down to the level of individual cells, optical coherence tomography with lower resolution but greater depth of penetration, electrical impedance spectroscopy that provides a score for the cellular irregularity of the skin based on electrical conductivity of the tissue, and multispectral analysis that involves illumination of the skin with different wavelength and likewise results in the computation of a score for structural irregularity [55]. Especially if used in combination, these techniques enhance the precision of the clinical diagnosis of melanoma (Figure 6A-C). Specificity and, especially, sensitivity have been claimed to exceed $90 \%$ with these techniques. Those numbers, however, have little significance because they depend strongly on the experience of the investigator and, especially, on the type of lesions examined. At very early stages, diagnosis is far less precise than in more advanced lesions, no matter which technique is employed.

\section{Increase in the Number of Biopsies}

The rationale for the use of adjunctive techniques for clinical diagnosis is the desire to reduce the frequency of biopsies for suspicious pigmented lesions. In fact, numerous studies have demonstrated a decrease in biopsies following dermatoscopic assessment of pigmented lesions. However, some studies also 
reported the opposite, namely, an increase in the number of lesions found to be suspicious dermatoscopically, compared to examination of them with the naked eye, that were found to be nevi histopathologically [56]. Likewise, data for confocal laser microscopy are contradictory. Some studies reported a significant decrease in biopsy rates [57], whereas others found that the enhanced sensitivity of diagnosis of melanoma was associated with a decrease in specificity that resulted in biopsy of melanocytic nevi [58]. The same obtains for multispectral analysis [59]. One reason may be the occasional presence in nevi of changes normally indicating malignancy, such as melanocytes in the upper reaches of the epidermis that are an expected finding in irritated nevi and in nevi on "special sites" such as palms and soles. Histopathologic examination allows those findings to be assessed in the context of many other criteria that helps to avoid overdiagnoses. In contrast, melanocytes in the upper reaches of the epidermis found by confocal laser microscopy result in the lesion being classified as suspicious and selected for biopsy. Lack of change of a lesion during follow-up indicates benignancy because melanocytic nevi are very stable once they have reached the stage of senescence. Accordingly, follow-up of patients with myriad pigmented lesions through total body photography has resulted in a significant decrease of biopsy rates [60]. On the other hand, if a lesion shows changes during follow-up, this alone may prompt a biopsy to be performed-although less than $10 \%$ of changing lesions have been found to be melanomas [61].

The number of nevi excised for each melanoma has been referred to as the "number needed to treat" and varies significantly in different studies; in a recent review numbers ranged between 4 and 29.9 [62]. The lower numbers may reflect the ratio in specialized centers but, in general, the higher numbers are probably closer to reality. In our own material, i.e., specimens examined in a big dermatopathology laboratory in Germany under the conditions of population-based skin cancer screening, the "number needed to treat" was 36.4 in three successive months of 2016. Epidemiologists are right to deplore that "biopsy samples are taken from hundreds of thousands of benign lesions ... In addition to needless morbidity, these interventions cost billions of dollars" [63].

The substantial increase in biopsies was associated not only with an increase in the number of excised nevi but also of melanomas. The latter paralleled the rise in biopsies. For example, in the United States, the number of biopsies increased between 1986 and 2001 by $154 \%$ and the number

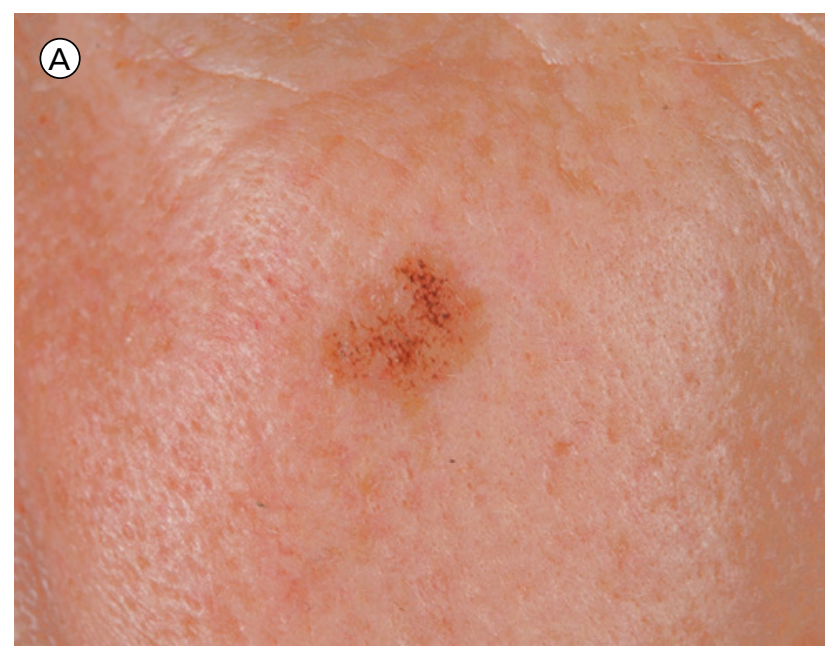

(B)
Figure 6A-C. Clinical, dermatoscopic, and confocal microscopic presentation of lentigo maligna demonstrating the potential of adjunctive techniques in the clinical diagnosis of melanoma (courtesy of Harald Kittler, Vienna). 
of melanomas by $140 \%$ [63]. The parallel increase in biopsies and melanomas raised doubts concerning the tale of a "melanoma epidemic" that had been accepted wholesale for many years. The "incredibly rising incidence of malignant melanoma" [64] suddenly seemed to be incredible. A moderate rise in the incidence could be expected, if only because of increased longevity, but the dramatic increase seemed to be artificial and could be explained by a variety of other factors, such as increased reporting of melanomas to tumor registries and more reliable criteria for histopathologic diagnosis [65]. In the old literature, there are scores of pictures of clear-cut melanoma misdiagnosed as melanocytic nevus. If lesions had been excised in toto and had not metastasized, patients would have never learned that they had been afflicted by a potentially life threatening neoplasm.

\section{Misleading Use of the Term "Overdiagnosis"}

Most melanomas accountable for the rise in incidence were lesions at an early stage. Formerly celebrated as a triumph of cancer screening, that fact suddenly raised doubts concerning the expedience of it. In 2005, Welch and coworkers noted that "the incidence of melanoma is associated with biopsy rates. That the extra cases diagnosed were confined to early stage cancer while mortality remained stable suggests overdiagnosis-the increased incidence being largely the result of increased diagnostic scrutiny and not an increase in the incidence of disease" [66].

The term "overdiagnosis" was not employed as in the traditional meaning of misdiagnosis. A new definition of that term had been advanced by epidemiologists in 1989 for breast cancer, namely, "a histologically established diagnosis of invasive or intraductal breast cancer that would never have developed into a clinically manifest tumour during the patient's normal life expectancy if no screening examination had been carried out" [67]. Although highly prone to be misunderstood, that definition has been embraced by epidemiologists worldwide and has been extended to all types of cancer. The definition, however, refers to a statistical variable exclusively and not to neoplasms in the real world because patients may outlive their "normal life expectancy" and nobody knows in advance whether or not an "invasive or intraductal ... cancer ... would ... have developed into a clinically manifest tumour" [67].

\section{Failure of Melanoma to Develop into a "Clinically Manifest Tumor"}

The hypothesis that the rise in the incidence of melanoma is caused primarily by “inconsequential cancer," i.e., melano- mas that would never have been noticed had they not been biopsied, implies the assumption that such melanomas also existed in the past without being treated and without resulting in higher morbidity and mortality. There are two possible explanations for that assumption. First, patients could have died of other causes before being bothered by their melanoma. Considering the advanced age of many patients with melanoma, that explanation is plausible. However, it does not explain the rise in the incidence of melanoma in children and young adults. If there were also melanomas in that age group that were never diagnosed and that never caused any trouble, they must have regressed spontaneously [68].

The second explanation, spontaneous regression, is also plausible considering the common occurrence of that phenomenon in melanoma. Most melanomas are associated with a marked inflammatory cell infiltrate as an expression of an immunologic response to them. That response often leads to partial regression of the neoplasm. In the center or, more often, at the edge of melanomas, melanocytes are diminished in number or absent entirely and, as a result of the preceding inflammatory process, the papillary dermis is fibrotic and contains melanophages and blood vessels with prominent endothelia arranged perpendicularly to the skin surface. If there are numerous melanophages, zones of regression are difficult to distinguish clinically from other areas of the neoplasm, whereas cases with marked fibrosis of the papillary dermis and few melanophages present themselves as poorly pigmented or whitish zones.

Histopathologically, signs of regression may be apparent readily but may also be very subtle, sometimes consisting of nothing but slight fibrosis with an occasional melanophage. Those subtle signs of regression can be overlooked easily and may result in recurrences of the primary tumor in cases in which the latter seems to have been removed completely with a generous margin. If regression continues, it may lead to complete disappearance of the neoplasm. According to the literature, no primary melanoma can be detected in 2 to $8 \%$ of all metastasizing melanomas [69], a phenomenon caused most commonly by complete regression of it. If advanced melanomas that have caused metastases regress so often, how much more common must be complete regression in early melanomas that have not metastasized and that will never be noticed, unless a biopsy is taken prior to their complete disappearance [68]? The latter circumstance has become much more common because of efforts to detect them early-on; when confronted with melanomas in nearly complete regression, one sometimes wishes that the clinician had postponed his biopsy by half a year (Figure 7A-C).

That some melanomas "would never have developed into a clinically manifest tumour" is beyond dispute [67]. However, to attribute the rise in the incidence of melanomas entirely to that phenomenon is just as one-sided as the tale 

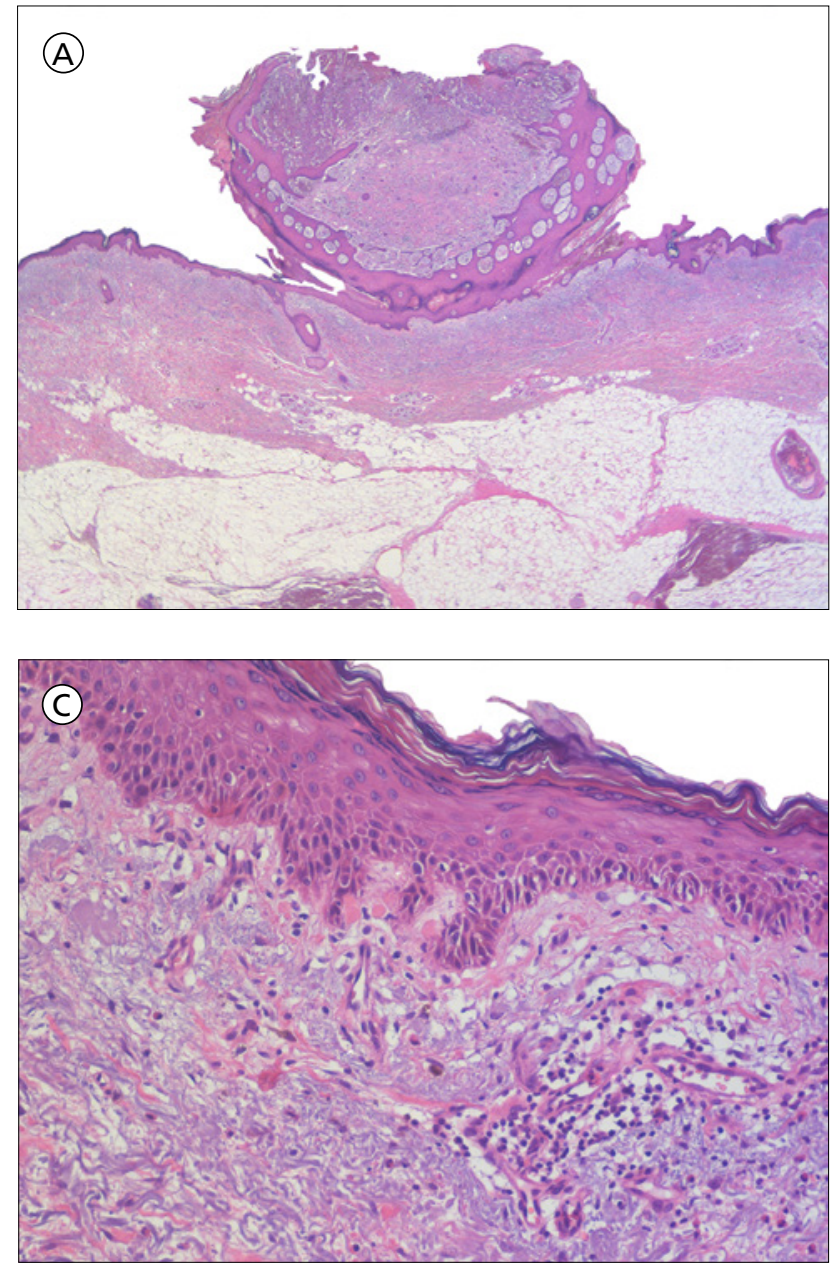

of a true "melanoma epidemic." Obviously, various factors play a role: an increase in detection and treatment melanomas that would have progressed and caused death in the absence of treatment, an increase in melanomas that would have remained "inconsequential" without such measures, and a real rise in the incidence of melanoma. That the latter exists is suggested by an increase in the number of thick melanomas in populations not participating in cancer screening [70]. Moreover, only a real rise in the incidence of melanoma explains the sustained high mortality rates because it is fallacious to assume that excision of many more melanomas at an early stage has no beneficial effect at all.

After all, we are not entirely ignorant about how melanomas behave biologically. Although, for obvious ethical reasons, there have been no long-term prospective studies concerning their natural biologic course; experience of many decades suggests that melanomas, irrespective of stage, tend to progress. Photokatamnestic studies of patients with advanced melanomas demonstrated their slow but inexorable growth over many years [71]. Dermatoscopic follow-up studies of suspicious lesions that eventually proved to be melanoma demonstrated their slow but continuous expansion and a behavior of growth that differed clearly from that of melano-

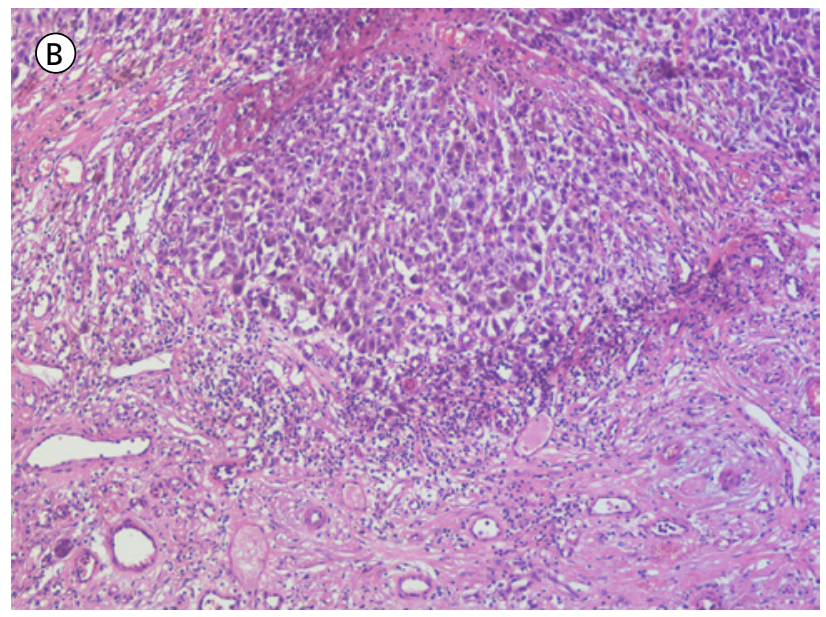

Figure 7A. Exophytic melanoma in nearly complete regression. Neoplastic cells have given way to granulation tissue in the exophytic nodule and to superficial fibrosis adjacent to it. In the nodule, small aggregations of neoplastic cells have remained. [Copyright: (C2018 Weyers.]

Figure 7B. A dense lichenoid infiltrate of lymphocytes is present beneath remnants of epithelioid melanoma cells with pronounced nuclear atypia. Beneath the infiltrate, neoplastic cells have been substituted by granulation tissue. [Copyright: (C2018 Weyers.]

Figure 7C. In the periphery, only moderate fibrosis of the papillary dermis with dilated, thick-walled blood vessels, some colloid bodies, and a few melanophages signify that the melanoma was once far larger. [Copyright: (C2018 Weyers.]

cytic nevi [50]. A study of 50 incipient melanomas followed dermatoscopically demonstrated a mean growth rate of 5.3 $\mathrm{mm}^{2}$ per year [72]. Following incomplete removal of melanomas, recurrences are common, probably even the rule, a characteristic that caused melanomas to become the most frequent source of medical malpractice suits in the United States [73].

\section{Curtailment of Screening for a Potentially Life Threatening Tumor}

Nonetheless, the hypothesis that the increased incidence of melanoma is "largely the result of increased diagnostic scrutiny and not an increase in the incidence of disease" [66] has found wide acceptance and has resulted in demands to curtail diagnostic scrutiny. In recent years, it has been suggested by epidemiologists that "screening guidelines should be revised to lower the chance of detection of ... inconsequential cancers with the same energy traditionally used to increase the sensitivity of screening tests" [63]. The cost of population-based screening for melanoma has been criticized, and it is estimated that 25,000 screening examinations are necessary to prevent a single death from melanoma, whereas other cancers show a far more favorable ratio, 
e.g., only 800 examinations are necessary arithmetically to prevent one fatality in colon carcinoma [74].

Accordingly, it has been suggested that screening be confined to individuals with an enhanced risk of developing melanoma, such as those with myriad nevi and a family history of melanoma; however, most melanomas occur in patients not belonging to such risk groups. The importance of screening also depends on the level of knowledge of melanoma in the population. If the risk associated with an unsual or changing mole is known, and patients with such a lesion would attend a physician anyhow, regular screening is less effective because it results in only slight preponement of the time of diagnosis and treatment. Hence, "shortening the delay in the diagnosis by intensifying education and screening of the whole population may not lead any longer to a strong improvement of prognosis" [75]. In fact, numerous studies have shown that the majority of melanomas are self-detected or detected by family members [76-78]. Because of direct visibility, screening for skin lesions is less urgent than for neoplasms such as colon carcinoma that cannot be noticed at an early stage by patients themselves.

\section{Denial of the Malignant Nature of Melanoma at an Early Stage}

The unhesitant acceptance of the speculation that the rise in melanoma incidence is caused primarily by removal of basically harmless lesions, and the dominant role that speculation acquired, in the absence of any sound evidence, in subsequent debates about screening can be explained only by its coincidence with another development commencing at that time, namely, a renaissance of concepts in dermatopathology that seemed to have been overcome. By acknowledging that most criteria for histopathologic diagnosis of melanoma pertain to changes in the epidermis, diagnosis of melanoma had become possible at the in situ stage. Although diagnosis may be difficult at that stage, it is straightforward and undisputable in cases in which all criteria are fulfilled, including asymmetry; poor circumscription by solitary melanocytes; uneven distribution of solitary melanocytes, nests, and pigment; focal predominance of solitary melanocytes over nests; variation in size and shape of nests; and presence of pagetoid melanocytes in all reaches of the epidermis. However, melanomas detected at that stage are still harmless biologically; in the new terminology of epidemiologists, they qualify as "indolent cancer" or "inconsequential cancer." It is the very purpose of screening to detect and to remove "inconsequential" lesions in order to prevent them from becoming "consequential." Nonetheless, the logic of screening was turned upside-down by arguing that melanoma in situ cannot cause death and, therefore, is not malignant. For example, Clark, in 1990, referred to melanoma in situ as "a contradiction in terms, the prototype of an oxymoron" [79], and Juan Rosai, in 2008, spoke of it as an "obsolete, untenable concept" [80].

Although Clark himself had been among the first to emphasize that most melanomas do not arise in association with a nevus, that "the junction nevus has no formal histogenetic relationship to malignant melanoma," and that "most malignant melanomas pass through a long phase of superficial growth during which the process differs in appearance from junctional nevi" [81], he subsequently presented melanoma as a model for the theory of multistep carcinogenesis, according to which malignant neoplasms arise from "precursor lesions" through accruing genetic alterations and came "to view melanocytic neoplasia as a paradigm for all neoplastic systems" [82]. In 1984, Clark and coworkers postulated a stepwise "tumor progression" from the "common acquired melanocytic nevus" via nevi with increasing "melanocytic dysplasia" to primary and metastatic melanoma. The "dysplastic nevus" was said to be the "histogenetic precursor of melanoma," and early stages of melanoma, including thin invasive lesions, were claimed not to be fully malignant because the authors "hypothesized that such tumors do not have competence for metastases," the latter being conferred to them through additional genetic alterations that launched melanoma into the "vertical growth phase" [82]. Incipient melanomas that fulfilled all histopathologic criteria for diagnosis were no longer diagnosed as melanoma but as nevi with "severe dysplasia" in order to adhere to the concept of tumor progression through successive "precursor lesions" [83].

That old concept has been reanimated recently by the demonstration of mutations shared by melanocytic nevi and melanomas, with additional mutations accumulating in the course of melanoma development. In principle, each and every mutation among the many hundreds detectable in advanced melanomas may be viewed as a new step of tumor progression, but the genetic findings were interpreted in accordance with concepts of the 1980s. Once again, melanoma in situ was said not to be malignant. Together with "intermediate lesions," including dysplastic nevi, it was referred to as a "precursor lesion" and was distinguished explicitly from melanoma [84]. Some authors even contended that in-situ melanomas are biologically distinct from invasive melanoma and that they are a different type of neoplasm affecting other age groups and different anatomic sites, and "not in themselves ... precursor lesions, but perhaps ... instead markers for increased risk of development of invasive melanomas" [85]. The tendency to deny the malignant nature of incipient melanomas coalesced with speculations concerning "overdiagnosis" of melanoma in precarious fashion-precarious because it may be dangerous to trivialize melanoma in situ. In-situ melanomas are no less melanomas than the same type of lesion at a slightly later stage. Their appearance, clinically and histopathologically, is identical to the macular component of advanced melanomas, 


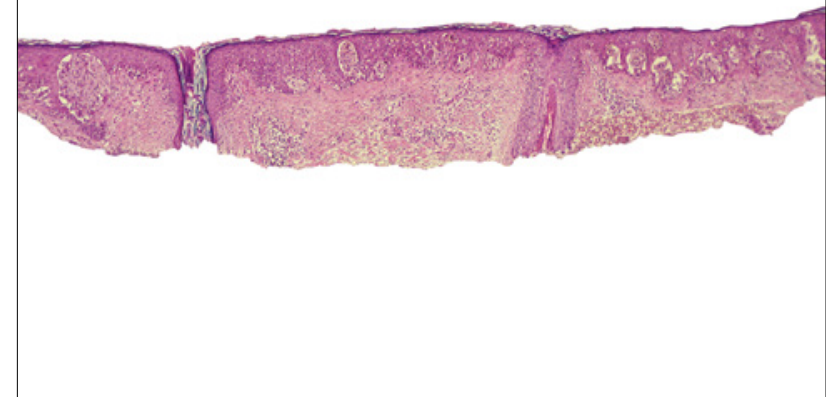

Figure 8. Melanoma in situ fulfilling all criteria for malignancy, namely, high cellularity, irregular size and form of nests, irregular distribution of nests and of solitary melanocytes, focal predominance of solitary melanocytes over nests, and many melanocytes in the upper reaches of the epidermis. This is melanoma and not a "precursor," irrespective of whether or not additional step sections reveal some melanocytes in the papillary dermis. [Copyright: (C2018 Weyers.]

and the morphologic correlates of biologic behavior-from high cellularity to uneven distribution of cells, extension of melanocytes deep down adnexal epithelia, and scatter of them through all levels of the epidermis-suggest that the decisive steps in cancerogenesis responsible for the malignant nature of the lesion have already occurred even if many additional clinical, histopathologic, and molecular changes may follow as the lesion progresses (Figure 8).

Lesions may also regress, but occasional regression of incipient melanomas does not militate against malignancy; spontaneous regression has also been reported in cases of melanoma with disseminated metastases [86]. In early lesions, that phenomenon is doubtlessly more common, but experience suggests that complete regression is an exception rather than the rule. At an early stage, there is usually no urgency in diagnosis, and lesions can be followed clinically for some time until the diagnosis can be made with confidence. However, at least in young patients, one cannot expect untreated melanomas to remain "inconsequential" for their lifetime. And even if a substantial share of melanomas currently detected early on would remain "inconsequential," early diagnosis and treatment cannot be discarded as superfluous as long as the future course cannot be foretold. Although epidemiologists have demanded "to focus on distinguishing indolent from aggressive disease" [87] and to reserve the designation "cancer" for "lesions with a reasonable likelihood of lethal progression if left untreated" [32], no prescription has been offered on how to accomplish this. Even Welch conceded that "the conundrum in overdiagnosis is that clinicians can never know who is overdiagnosed at the time of cancer diagnosis"
[88]. There is no marker that allows one to predict future behavior reliably, and such as marker will probably never emerge because behavior is not only determined by the lesion itself but by many unrelated factors, such as the immune response to it. In patients of advanced age, it may be justifiable to ignore a melanoma, but it is risky if one cannot gauge how much lifetime they have left. To count on spontaneous regression of melanoma in young and middle-aged patients would be negligent.

\section{The Problem of "True" Overdiagnosis: Misdiagnosis of Nevi as Melanoma}

In addition to death of patients from other causes and complete regression, there is yet another explanation for "melanomas" that "would never have developed into a clinically manifest tumour," namely, overdiagnosis—not "overdiagnosis" by epidemiologists but overdiagnosis in the traditional meaning of that term, i.e., misdiagnosis of melanocytic nevi as melanoma. Such overdiagnoses probably contribute substantially to the alleged rise in the incidence of melanoma [89,90]. Although diagnosis of melanoma is usually reliable thanks to numerous well-established criteria, there are exceptions. Among them are melanocytic neoplasms in which criteria are conflicting, such as Spitz's nevi which are usually symmetrical and sharply circumscribed but harbor melanocytes with pronounced nuclear atypia in all reaches of the epidermis. Depending on the degree of those changes, distinction from melanoma may be extremely difficult. The same is true for nevi "in special sites," such as acral skin or genitalia, that may display features normally indicating malignancy, such as pronounced confluence of nests and melanocytes above the junction. In addition to those problems of differential diagnosis caused by conflicting criteria, there are problems caused by lack of criteria. The latter have become much more common in recent years and are more relevant for the problem of overdiagnosis.

One of the chief reasons for that detrimental development are efforts to detect and remove melanomas as early as possible. More and more biopsies are being performed in lesions measuring only 2,3 , or $4 \mathrm{~mm}$ in diameter. Clinically, those lesions present themselves as a dark-brown or black macule that does not allow for a clear distinction between nevus and melanoma because it was not given the time to develop features that make it recognizable. Dermatoscopy and confocal laser microscopy may reveal more distinctive features, but those adjunctive techniques also reach their limits in lesions of that size. Because a clear-cut distinction between a nevus and a melanoma is often impossible in such lesions, the latter are biopsied, and histopathologists are confronted with the same problem: the lesions did not have enough time to develop features crucial for histopathologic differential diagnosis, just 

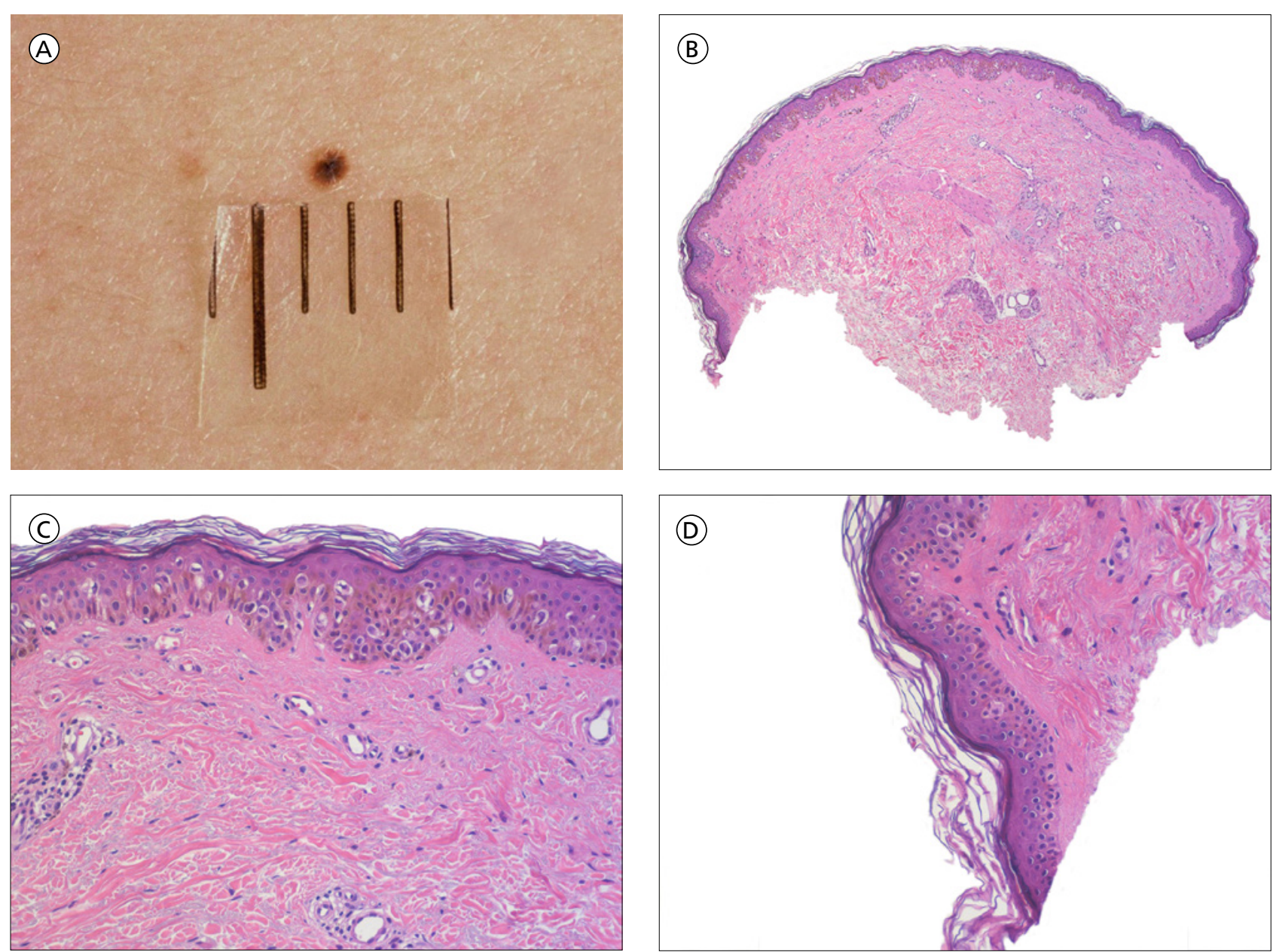

Figure 9A. Small melanocytic neoplasm measuring $2 \mathrm{~mm}$ in diameter. At this early stage, a definite clinical distinction between Clark's nevus and melanoma in situ is not yet possible because, in the latter instance, the lesion did not have enough time to develop features indicating malignancy, such as an irregular border or irregular distribution of pigment. [Copyright: (O2018 Weyers.]

Figure 9B. The lesion was removed. Histopathologically, it is composed of solitary melanocytes only. Predominance of solitary melanocytes over nests is a criterion for malignancy that cannot be applied to such early lesions. [Copyright: @2018 Weyers.]

Figure 9C. The regular distribution for solitary melanocytes is in favor of benignancy. However, presence of numerous melanocytes above the basal layer in the absence of signs of irritation is unusual for a melanocytic nevus. A melanoma in situ cannot be excluded with confidence. [Copyright: @2018 Weyers.]

Figure 9D. The lesion was probably excised completely, but it comes close to one lateral margin. Incomplete excision cannot be excluded. If this is a nevus, excision of it qualifies as "overtreatment" in the first place. Because a melanoma in situ cannot be ruled out, and the lesion may have been excised incompletely, a re-excision was performed, probably “double overtreatment.” [Copyright: @2018 Weyers.]

as an embryo at an early stage does not allow for distinction between male and female or between mouse and man.

For example, one criterion for malignancy, focal predominance of solitary melanocytes over nests, cannot be employed if nests have not yet formed. Likewise, poor circumscription by solitary melanocytes rather than nests is a criterion for malignancy, but if there are no nests, it is fulfilled by all melanocytic lesions (Figure 9A-D). It is not surprising, therefore, that the reliability of histopathologic diagnosis in small pigmented lesions is poor. A larger study with a participation of 187 American pathologists found that "diagnoses of melanoma in situ and early stage invasive melanoma ... were neither reproducible nor accurate" [91]. A study from Austria revealed marked regional differences in the diagnosis of melanoma in situ: pathologists employed different criteria for diagnosis in different areas of the country [92]. In a study of melanomas measuring $4 \mathrm{~mm}$ in diameter or less, only half were unanimously diagnosed as melanoma upon review by each of three dermatopathologists. The authors suggested adopting "a 'consensus diagnosis' approach among histopathologists, because these lesions have no true gold standard" [93].

\section{Incomplete Excision as an Important Cause of Overdiagnosis of Melanoma}

The reliability of histopathologic diagnosis is diminished even further if lesions are not excised completely because, in that 
case, additional criteria for diagnosis cease to be available, such as symmetry and circumscription. Unfortunately, partial biopsies are becoming more and more common. Despite demands that incisional biopsies should be performed only for distinction of melanocytic from non-melanocytic neoplasms, and not for distinguishing nevi from melanomas, they are being performed indiscriminately for all kinds of melanocytic neoplasms by an ever increasing number of dermatologists; in the United States, most melanomas are currently diagnosed on the basis of partial biopsies. This course of action reduces the dependability of diagnosis substantially and cannot be corrected by subsequent re-excision because most re-excision specimens show no or only small remnants of the neoplasm that defy meaningful interpretation. Moreover, the previous procedure may result in signs of irritation, such as presence of melanocytes above the junction, impeding diagnosis even more. Incomplete excisions with a markedly reduced chance of correct diagnostic interpretation may be the most important cause of overdiagnosis. The reason is the disparity in the consequences of an incorrect diagnosis. If a benign lesion is misinterpreted as malignant, the mistake is hardly ever uncovered, whereas a malignant lesion misinterpreted as benign may recur and, in addition to damage to the patient, may have a legal aftermath for the histopathologist. In cases lacking sufficient criteria for diagnosis, this is a strong incentive to err on the malignant side $[89,90]$.

Of course, histopathologists may choose to acknowledge uncertainty and abstain from a specific diagnosis. In general, however, there is no fallback for them, as for clinicians who, in the case of doubt, perform a biopsy and delegate responsibility to the histopathologist. Traditionally, histopathology is considered to be the "gold standard" for the diagnosis of neoplasms. In the past decades, numerous studies have shown how far from "gold" this standard is. Nonetheless, despite many limitations, histopathology is better suited to fulfill that role than other techniques, although clinical or dermatoscopic findings may be more revealing in individual cases. Histopathologic diagnosis of a neoplasm is only rarely overruled by other considerations. Having the last word, histopathologists are pressed to offer a final conclusion, usually in the form of a clear-cut diagnosis. If the latter is not provided, they must at least utter some judgment leading, most often implicitly, to a suggestion concerning management of the patient. In the case of doubts being spelled out, the consequences are usually identical to those produced by a diagnosis of malignancy, such as a re-excision, and the emotional burden for the patient is comparable.

Overdiagnoses and evasive diagnoses are most common in very small lesions. The reason, in addition to diagnostically important features not yet having emerged, is the disproportionate number of inappropriate biopsies of those lesions that, in principle, should be those most suitable for complete excision. Not uncommonly, only fragments of epithelium are provided. The most likely explanation for that phenomenon is a low degree of suspicion on the part of clinicians because lesions of that size also lack clinical criteria for malignancy. With a lesion considered to be probably benign, physicians may flinch from taking a generous biopsy and may attach greater importance to a favorable cosmetic result. Furthermore, the generous execution of biopsies-with biopsies being taken from lesions measuring only 2 or $3 \mathrm{~mm}$ in diameter-often leads to removal of many lesions and attempts to perform biopsies as simply and quickly as possible. The diligence attached to each biopsy, and the appraisal of the importance of diligence, are lower than with a more reserved approach.

\section{Diagnosed “Too Early”}

In other words, the formula of "the earlier, the better" that has replaced the old conviction of noli me tangere cannot be accepted without reservation. There is also such a thing as "too early" in which an active approach may be detrimental, rather than beneficial. Linking the indication for biopsy to the old $\mathrm{ABCD}$ rule for clinical recognition of melanoma has been suggested recently. In a retrospective analysis of lesions biopsied under the clinical suspicion of melanoma, "lesions larger than $6 \mathrm{~mm}$ in size had higher positive predictive value," and restriction of biopsies to those lesions would result in a substantial reduction of the "number needed to treat" [94]. Additional advantages not noted in that study include a substantial improvement of the reliability of histopathologic diagnosis and, possibly, greater diligence in performing the biopsy, again resulting in specimens easier to evaluate.

The incidence of melanomas smaller than $6 \mathrm{~mm}$ in diameter that have already invaded the dermis is not precisely known. Several studies suggest that about one-third of such small melanomas possess a dermal component. The latter, however, is nearly always superficial so that a simple excision results in permanent cure in the vast majority of patients $[93,95,96]$. Recent studies suggest that the delay in diagnosis caused by clinical observation of vaguely suspicious lesions of small diameter has no significant effect on the thickness of lesions at the time of biopsy and, therefore, is unlikely to affect prognosis $[97,98]$. There are rare exceptions of fatal small melanomas, but in the latter cases, lesions usually show a different biologic behavior from the outset: they often grow rapidly and present themselves as a small, firm papule that may not be pigmented clinically. Because of those qualities, such melanomas are usually not detected at an early stage [74], and they often evade screening efforts and are noticed by patients themselves as "interscreening cancers." Scrutiny for melanoma should focus on those 
lesions, and if a small, rapidly growing firm papule is noted, it should be biopsied without delay, especially if pigment can be detected dermatoscopically, even if it is smaller than 6 $\mathrm{mm}$ in diameter $[99,100]$.

There may also be other reasons to deviate from the rule to refrain from biopsies in lesions smaller than $6 \mathrm{~mm}$ in diameter. If dermatoscopy, confocal laser microscopy or other techniques reveal findings highly suggestive of malignancy, histopathologic evaluation is warranted. In such cases, however, histopathologists should be alerted to the high degree of suspicion because histopathologic criteria for malignancy may drag behind clinical ones. As long as histopathologic examination serves as a gold standard for diagnosis of melanocytic neoplasms, and very small melanomas "have no true gold standard" histopathologically in a substantial proportion of cases [93], biopsy of small pigmented lesions should not be the rule but an exception. If clinicians follow pigmented lesions until they develop obvious signs of malignancy or reach a diameter of $6 \mathrm{~mm}$, the reliability of histopathologic diagnosis can be improved substantially. Moreover, a less generous approach to biopsy might result in more diligence devoted to that procedure, further enhancing the reliability of diagnosis. By allowing pigmented lesions to play themselves out until they reach a stage that makes them recognizable and enables an unequivocal diagnosis to be made in the vast majority of cases, overdiagnosis can be curtailed and management of patients improved substantially.

\section{References}

1. Kaposi M. Bösartige Neubildungen. In: Virchow R (Hrsg.). Handbuch der speziellen Pathologie und Therapie. Vol. VIII. Erlangen: Enke. 1872:466.

2. Miescher G. Melanom. In: Jadassohn J (Hrsg.). Handbuch der Haut- und Geschlechtskrankheiten, Zwölfter Band, dritter Teil. Geschwülste der Haut II. Berlin: Julius Springer. 1933:1118.

3. Delacrétaz J, Jaeger H. Die Melanome (Die malignen Melanome). In: Gottron HA, Schönfeld W, eds. Dermatologie und Venerologie. Vol IV. Stuttgart: Georg Thieme. 1960: 619.

4. Allen AC, Spitz S. Malignant melanoma: a clinicopathological analysis of the criteria for diagnosis and prognosis. Cancer. 1953;6:1-45.

5. Lane N, Lattes R, Malm J. Clinicopathological correlations in a series of 117 malignant melanomas of the skin of adults. Cancer. 1958;11:1025-1043.

6. Lund HZ, Kraus JM. Melanotic Tumors of the Skin. Atlas of Tumor Pathology, Section 1 - Fascicle 3. Armed Forces Institute of Pathology. 1962:56-59.

7. Price NM, Rywlin AM, Ackerman AB. Histologic criteria for the diagnosis of superficial spreading malignant melanoma: formulated on the basis of proven metastatic lesions. Cancer. 1976;38:2434-2441.

8. Weyers W. Criteria for diagnosis of melanoma histopathologically in historical perspective. Dermatopathology Practical \&
Conceptual. 2002;8:4. https://www.derm101.com/dpc-archive/ october-december-2002-volume-8-no-4/dpc0804a12-criteriafor-diagnosis-of-melanoma-histopathologically-in-historicalperspective/. Accessed November 6, 2017.

9. Swerdlow M. Nevi; a problem of misdiagnosis. Am J Clin Path. 1952;22:1054-1060.

10. Friedman RJ, Rigel DS, Kopf AW. Early detection of malignant melanoma: the role of physician examination and self-examination of the skin. CA Cancer J Clin. 1985;35:130-151.

11. Ackerman AB. No one should die of malignant melanoma. J Am Acad Dermatol. 1985:12:115-116.

12. Robinson WA. Malignant melanoma as a model for cancer education and prevention. 1989 Harvey lecture American Association for Cancer Education. J Cancer Educ. 1990;5:85-89.

13. Paul E. Das Melanom - ein idealer Vorsorgetumor. Bayer Ärztebl. 2004;7-8:400-402.

14. Wilson J, Jungner G. Principles and Practice of Screening for Disease. Geneva: World Health Organization. 1968: $26 \mathrm{f}$.

15. Cole P, Morrison AS. Basic issues in population screening for cancer. J Natl Cancer Inst. 1980;64:1263-1272.

16. McDonald CJ. Status of screening for skin cancer. Cancer. 1993;72:1066-1070.

17. Davis NC, Herron JJ. Queensland melanoma project: organization and a plea for comparable surveys. Med J Aust. 1966;1:643644.

18. Marks R. Two decades of the public health approach to skin cancer control in Australia: why, how and where are we now? Australas J Dermatol. 1999; 40: 1-5.

19. Montague M, Borland R, Sinclair C. Slip! Slop! Slap! and SunSmart, 1980-2000: skin cancer control and 20 years of population-based campaigning. Health Educ Behav. 2001;28:290-305.

20. Whiteman DC, Green AC, Olsen CM. The growing burden of invasive melanoma: projections of incidence rates and numbers of new cases in six susceptible populations through 2031. J Invest Dermatol. 2016;136:1161-1171.

21. Redman JC, Mora DB. Malignant melanoma of the skin diagnosed and treated in Albuquerque, New Mexico, in 1980. J Dermatol Surg Oncol. 1982;8:40-43.

22. Putnam GL, Yanagisako KL. Skin cancer comic book: evaluation of a public educational vehicle. Cancer Detect Prev. 1982;5:349356.

23. Boldeman C, Jansson B, Holm LE. Primary prevention of malignant melanoma in a Swedish urban preschool sector. $J$ Cancer Educ. 1991;6:247-253.

24. Hughes BR, Altman DG, Newton JA. Melanoma and skin cancer: evaluation of a health education programme for secondary schools. Br J Dermatol. 1993;128:412-417.

25. Illig L, Paul E, Hundeiker M. [Public and Professional Melanoma Education. A German model for improved early detection of melanomas by journalistic methods-based on corrected views on melanoma and nevus]. Z Hautkr. 1983;58:73-112.

26. Breitbart EW, Christophers E. Arbeitsgemeinschaft Dermatologische Prävention (ADP) e.V. J Dtsch Deratol Ges. 2014; 12 (Suppl. 4):42

27. Greinert R, Volkmer B, Wende A, et al. Prävention von Hautkrebs. Notwendigkeit, Durchführung und Erfolg. Hautarzt. 2003;54:1152-1163.

28. Breitbart EW, Waldmann A, Nolte S, et al. Systematic skin cancer screening in Northern Germany. J Am Acad Dermatol. 2012;66:201-211. 
29. Kaiser M, Schiller J, Schreckenberger C. The effectiveness of a population-based skin cancer screening program: evidence from Germany. Eur J Health Econ. 2017, March 28 (epub).

30. Breitbart EW, Choudhury K, Anders MP, et al. Benefits and risks of skin cancer screening. Oncol Res Treat. 2014;37(Suppl. 3):38-42.

31. Lucas RM, Norval M, Neale RE, et al. The consequences for human health of stratospheric ozone depletion in association with other environmental factors. Photochem Photobiol Sci. 2015;14:53-87.

32. Esserman LJ, Thompson IM Jr, Reid B, et al. Overdiagnosis and overtreatment in cancer: an opportunity for improvement. JAMA. 2013;310:797-798.

33. Criscone VD, Weinstock MA. Melanoma thickness trends in the United States, 1988-2006. J Invest Dermatol. 2010;130:793-797.

34. Weidner F, Hornstein OP, Bischof GM. Zur Treffsicherheit der klinischen Diagnose bei malignen Melanomen. Dermat Mschr. 1983;169:706-710.

35. Koh HK, Lew RA, Prout MN. Screening for melanoma/skin cancer: theoretical and practical considerations. J Am Acad Dermatol. 1989;20:159-172.

36. Grin CM, Kopf AW, Welkovich B, Bart RS, Levenstein MJ. Accuracy in the clinical diagnosis of malignant melanoma. Arch Dermatol. 1990;126:763-766.

37. Chamberlain AJ, Fritschi L, Kelly JW. Nodular melanoma: patients' perceptions of presenting features and implications for earlier detection. J Am Acad Dermatol. 2003;48:694-701.

38. Abbasi NR, Shaw HM, Rigel DS, et al. Early diagnosis of cutaneous melanoma: revisiting the ABCD criteria. JAMA. 2004; 292: 2771-6.

39. Slue W, Kopf AW, Rivers JK. Total-body photographs of dysplastic nevi. Arch Dermatol. 1988;124:1239-1243.

40. MacKie RM. Clinical recognition of early invasive malignant melanoma. BMJ. 1990;301:1005-1006.

41. Tran KT, Wright NA, Cockerell CJ. Biopsy of the pigmented lesion - when and how. J Am Acad Dermatol. 2008;59:851-871.

42. Grob JJ, Bonerandi JJ. The 'ugly duckling' sign: identification of the common characteristics of nevi in an individual as a basis for melanoma screening. Arch Dermatol. 2008;134:103-104.

43. Gaudy-Marqueste C, Wazaefi Y, Bruneu Y, et al. Ugly duckling sign as a major factor of efficiency in melanoma detection. JAMA Dermatol. 2017;153:279-284.

44. Pehamberger H, Steiner A, Wolff K. In vivo epiluminescence microscopy of pigmented lesions. I. Pattern analysis of pigmented skin lesions. J Am Acad Dermatol. 1987;17:571-583.

45. Nachbar F, Stolz W, Merkle T et al. The ABCD rule of dermatoscopy. High prospective value in the diagnosis of doubtful melanocytic skin lesions. J Am Acad Dermatol. 1994;30:551-559.

46. Menzies SW, Ingvar C, Crotty KA, McCarthy WH. Frequency and morphologic characteristics of invasive melanomas lacking specific surface microscopic features. Arch Dermatol. 1996;132:11781182.

47. Argenziano G, Fabbrocini G, Carli, P, De Giorgi V, Sammarco E, Delfino M. Epiluminescence microscopy for the diagnosis of doubtful melanocytic skin lesions. Comparison of the $\mathrm{ABCD}$ rule of dermatoscopy and a new 7-point checklist based on pattern analysis. Arch Dermatol. 1998;134:1563-1570.

48. Soyer HP, Argenziano G, Zalaudek I, et al. Three-point checklist of dermoscopy. A new screening method for early detection of melanoma. Dermatology. 2004;208:27-31.
49. Henning JS, Dusza SW, Wang SQ, et al. The CASH (color, architecture, symmetry, and homogeneity) algorithm for dermoscopy. J Am Acad Dermatol. 2007;56:45-52.

50. Kittler H, Guitera P, Riedl E, et al. Identification of clinically featureless incipient melanoma using sequential dermoscopy imaging. Arch Dermatol. 2006;142:1113-1119.

51. Kittler H, Pehamberger H, Wolff K, Binder M. Diagnostic accuracy of dermoscopy. Lancet Oncol. 2002; 3: 159-165.

52. Esteva A, Kuprel B, Novoa RA, et al. Dermatologist-level classification of skin cancer with deep neural networks. Nature. 2017;542:115-118.

53. Marchetti MA, Codella MCF, Dusza SW, et al. Results of the 2016 International Skin Imaging Collaboration International Symposium on biomedical imaging challenge: comparison of the accuracy of computer algorithms to dermatologists for the diagnosis of melanoma from dermoscopic images. J Am Acad Dermatol. 2017; 2017;78:270-277.

54. Korotkov K, Quintana J, Puig S, Malvehy J, Garcia R. A new total body scanning system for automatic change detection in multiple pigmented skin lesions. IEEE Trans Med Imaging. 2015:317-338.

55. Welzel J, Schuh S. Nicht-invasive Diagnostik in der Dermatologie. JDDG. 2017;15:999-1016.

56. Seidenari S, Longo C, Giusti F, Pellacani G. Clinical selection of melanocytic lesions for dermoscopy decreases the identification of suspicious lesions in comparison with dermoscopy without clinical preselection. Br J Dermatol. 2006;154:873-879.

57. Pellacani G, Pepe P, Casari A, Longo C. Reflectance confocal microscopy as a second-level examination in skin oncology improves diagnostic accuracy and saves unnecessary excisions: a longitudinal prospective study. Br J Dermatol. 2014;171:1044-1051.

58. Carrera C, Marghoob AA. Discriminating nevi from melanomas: clues and pitfalls. Dermatol Clin. 2016;34:395-409.

59. Rigel DS, Roy M, Yoo J, Cockerell CJ, Robinson JK, White R. Impact of guidance from a computer-aided multispectral digital skin lesion analysis device on decision to biopsy lesions clinically suggestive of melanoma. Arch Dermatol. 2012;148:541-543.

60. Truong A, Strazzulla L, March J, et al. Reduction in nevus biopsies in patients monitored by total body photography. J Am Acad Dermatol. 2016;75:134-143.

61. Salerni G, Carrera C, Lovatto L, et al. Characterization of 1152 lesions excised over 10 years using total-body photography and digital dermatoscopy in the surveillance of patients at high risk for melanoma. J Am Acad Dermatol. 2012;67:836-845.

62. Sidhu S, Bodger O,Williams N, Roberts DL. The number of benign moles excised for each malignant melanoma: the number needed to treat. Clin Exp Dermatol. 2012;37:6-9.

63. Esserman LJ, Thompson IM, Reid B, et al. Addressing overdiagnosis and overtreatment in cancer: a prescription for change. Lancet Oncol. 2014;15:e234-242.

64. Kopf AW. The incredibly increasing incidence of malignant melanoma in the USA. Schrift Marchionini-Stiftg. 1985;9: 2934.

65. Bozzo PD. There is no epidemic of melanoma! Dermatopathology Practical \& Conceptual. 1998;4(2):124-126. https://www. derm101.com/dpc-archive/apr-jun-1998-vol-4-no-2/dpc0402a04there-is-no-epidemic-of-melanoma/. Acccessed November 11, 2017.

66. Welch HG, Woloshin S, Schwartz LM. Skin biopsy rates and incidence of melanoma: population based ecological study. BMJ. 2005;331:481. 
67. Peeters PHM, Verbeek ALM, Straatman H, et al. Evaluation of overdiagnosis of breast cancer in screening with mammography: results of the Nijmegen programme. Int J Epidemiol. 1989;18:295-299.

68. Weyers W. The 'epidemic' of melanoma between under- and overdiagnosis. J Cutan Pathol. 2012;39:9-16.

69. Savoia P, Fava P, Osella-Abate S, et al. Melanoma of unknown primary site: a 33-year experience at the Turin Melanoma Centre. Melanoma Res. 2010;20:227-232.

70. Linos E, Swetter SM, Cockburn MG, Colditz GA, Clark CA. Increasing burden of melanoma in the United States. J Invest Dermatol. 2009;129:1666-1674.

71. Paul E. Wachstumsdynamik maligner Melanome. Fortschr Med. 1989; 107: 97-102.

72. Beer J, Xu L, Tschandl P, Kittler H. Growth rate of melanoma in vivo and correlation with dermatoscopic and dermatopathologic findings. Dermatol Pract Concept. 2011;1(1): 59-67.

73. Rayess HM, Gupta A, Svider PF, et al. A critical analysis of melanoma malpractice litigation; should we biopsy everything? Laryngoscope. 2017; 127:134-139.

74. Gilmore S. Melanoma screening: informing public health policy with quantitative modelling. PLoS One. 2017;12(9):e0182349.

75. Richard MA, Grob JJ, Avril MF, et al. Melanoma and tumor thickness: challenges of early diagnosis. Arch Dermatol. 1999;135:269274.

76. Richard MA, Grob JJ, Avril MF, et al. Delays in diagnosis and melanoma prognosis (I): the role of patients. Int J Cancer. 2000;89:271-279.

77. Carli P, De Giorgi V, Palli D, et al. Self-detected cutaneous melanomas in Italian patients. Clin Exp Dermatol. 2004; 29: 593-596.

78. Lee KB, Weinstock MA, Risica PM. Components of a successful intervention for monthly skin self-examination for early detection of melanoma: the "Check-it-out" trial. J Am Acad Dermatol. 2008;58:1006-1012.

79. Clark WH Jr, Malignant melanoma in situ. Hum Pathol. 1990;21:1197-1198.

80. Rosai J. [Lecture]. Melanoma in situ: an attractive, obsolete, untenable concept. Graz: 29th Symposium of the International Society of Dermatopathology, Oct 4, 2008.

81. Clark WH Jr, From L, Bernardino MA, Mihm MC. The histogenesis and biologic behavior of primary human malignant melanomas of the skin. Cancer Res. 1969;29:705-727.

82. Clark WH Jr, Elder DE, Guerry D IV, Epstein MN, Green MH, Van Horn M. A study of tumor progression: the precursor lesions of superficial spreading and nodular melanoma. Hum Pathol. 1984;15:1147-1165.

83. Reed RJ, Clark WH Jr, Mihm MC. Premalignant melanocytic dysplasias. In: Ackerman AB (ed.) Pathology of Malignant Melanoma. New York: Masson. 1981:159-183.

84. Shain AH, Yeh I, Kovalyshyn I, et al. The genetic evolution of melanoma from precursor lesions. N Engl J Med. 2015;373:19261936.
85. Wie EX, Quereshi AA, Han J, et al. Trends in the diagnosis and clinical features of melanoma in situ (MIS) in US men and women: a prospective, observational study. J Am Acad Dermatol. 2016;75:698-705.

86. Bramhall RJ, Mahady K, Peach AH. Spontaneous regression of metastatic melanoma - clinical evidence of the abscopal effect. Eur J Surg Oncol. 2014;40:34-41.

87. Esserman L. Thompson I. Solving the overdiagnosis dilemma. J Natl Cancer Inst. 2010;102:58258-58253.

88. Welch HG, Black WC. Overdiagnosis in cancer. JNCI. 2010;102:605-613.

89. Glusac E. The melanoma 'epidemic', a dermatopathologist's perspective. J Cutan Pathol. 2011;38:264-267.

90. Weyers W. Forward to the past-oncology between underdiagnosis and overtreatment. Am J Dermatopathol. 2016;38:517-528.

91. Elmore JG, Barnhill RL, Elder DE, et al. Pathologists' diagnosis of invasive melanoma and melanocytic proliferations: observer accuracy and reproducibility study. BMJ. 2017;357: j2813.

92. Monshi B, Vujic M, Kivaranovic D. The burden of malignant melanoma. lessons to be learned from Austria. Eur J Cancer. 2016;56:45-53.

93. Ferrara G, Tomasini C, Argenziano G, Zalaudek I, Stefanato CM. Small-diameter melanoma: toward a conceptual and practical reappraisal. J Cutan Pathol. 2012;39:721-723.

94. Soltani-Arabshahi R, Sweeney C, Jones B, Florell SR, Hu N, Grossman D. Predictive value of biopsy specimens suspicious for melanoma: support for $6 \mathrm{~mm}$-criterion in the $\mathrm{ABCD}$ rule. $J \mathrm{Am}$ Acad Dermatol. 2015;72:412-418.

95. Shaw HM, McCarthy WH. Small-diameter malignant melanoma: a common diagnosis in New South Wales, Australia. J Am Acad Dermatol. 1992;27:679-682.

96. Abbasi NR, Yancovitz M, Gutkowicz-Krusin D, et al. Utility of lesion diameter in the clinical diagnosis of cutaneous melanoma. Arch Dermatol. 2008;144:469-474.

97. Baade PD, English DR, Youl PH, McPherson M, Elwood JM, Aitken JF. The relationship between melanoma thickness and time to diagnosis in a large population-based study. Arch Dermatol. 2006;142:1422-1427.

98. Rosina P, Tessari G, Giordano MV, Girolomoni G. Clinical and diagnostic features of in situ melanoma and superficial spreading melanoma: a hospital based study. J Eur Acad Dermatol Venereol. 2012;26:153-158.

99. Menzies SW, Moloney FJ, Byth K, et al. Dermoscopic evaluation of nodular melanoma. JAMA Dermatol. 2013;149:699-709.

100. Cicchiello M, Lin MJ, Pan Y, McLean C, Kelly JW. An assessment of clinical pathways and missed opportunities for the diagnosis of nodular melanoma versus superficial spreading melanoma. Australas J Dermatol. 2016;57:97-101. 